\title{
Chest wall reconstruction using a combined musculocutaneous anterolateral-anteromedial thigh flap
}

\author{
Pearlie W. W. Tan, Chin-Ho Wong, Heng-Nung Koong ${ }^{1}$, Bien-Keem Tan \\ Departments of Plastic, Reconstructive and Aesthetic Surgery, Singapore General Hospital, 'Department of Surgical Oncology, \\ National Cancer Center Singapore.
}

Address for correspondence: Dr. Bien-Keem Tan, FRCS. Singapore General Hospital, Outram Road, Singapore - 169608.

E-mail: bienkeem@singnet.com.sg

\section{ABSTRACT}

We present a massive $25 \mathrm{~cm} \times 20 \mathrm{~cm}$ chest wall defect resulting from resection of recurrent cystosarcoma phyllodes of the breast along with six ribs exposing pleura. The chest wall was reconstructed with a Prolene mesh-methylmethacrylate cement sandwich while soft tissue reconstruction was carried out using a combined free anterolateral-anteromedial thigh musculocutaneous flap with two separate pedicles, anastomosed to the thoracodorsal and thoracoacromial vessels respectively. We explain our rationale for and the advantages of combining the musculocutaneous anterolateral thigh flap with the anteromedial-rectus femoris thigh flap.

\section{KEY WORDS}

Anterolateral thigh flap; anteromedial thigh flap; chest wall defects; combined free flap

\section{INTRODUCTION}

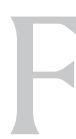

or a large chest wall defect measuring $425 \mathrm{~cm} \times 20 \mathrm{~cm}$ resulting from the excision of a recurrent cystosarcoma phyllodes involving ribs 4 to 9 , skeletal stabilization was provided by a prolene mesh - methylmethacrylate sandwich and the soft tissue repair was done by a combined anterolateral and anteromedial thigh flap on two separate vascular pedicles. Along with the case description we present the vascular anatomy of this dual flap.

\section{CASE REPORT}

A 52-year-old woman presented with recurrent cystosarcoma phyllodes of the left breast 12 years after primary resection [Figure 1].

Intra-operatively, a large tumour measuring $12 \mathrm{~cm}$ transversely was found adherent to the chest wall, invading the skin, ribs and pleura. The thoracic surgeon resected the entire left anterolateral chest wall from the midsternum to the midaxillary line, comprising skin,

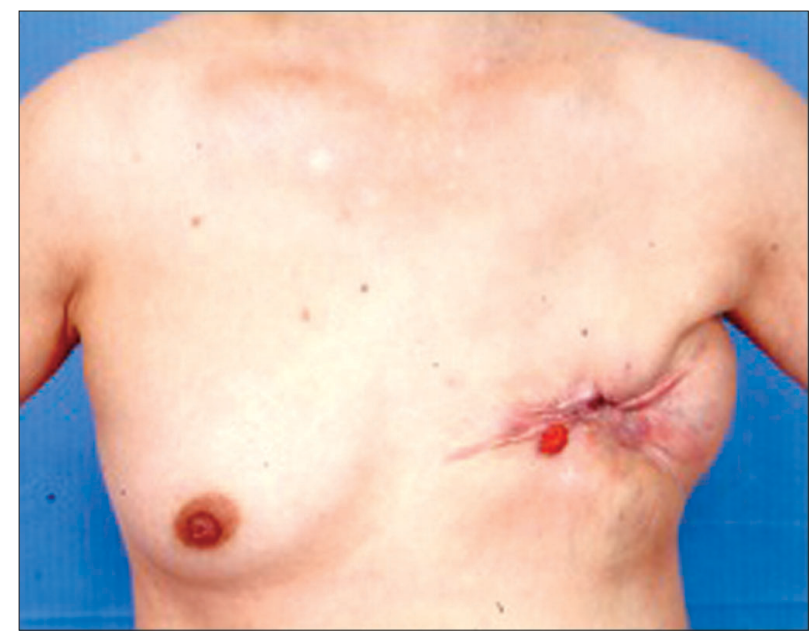

Figure 1: Recurrent cytosarcoma phyllodes 


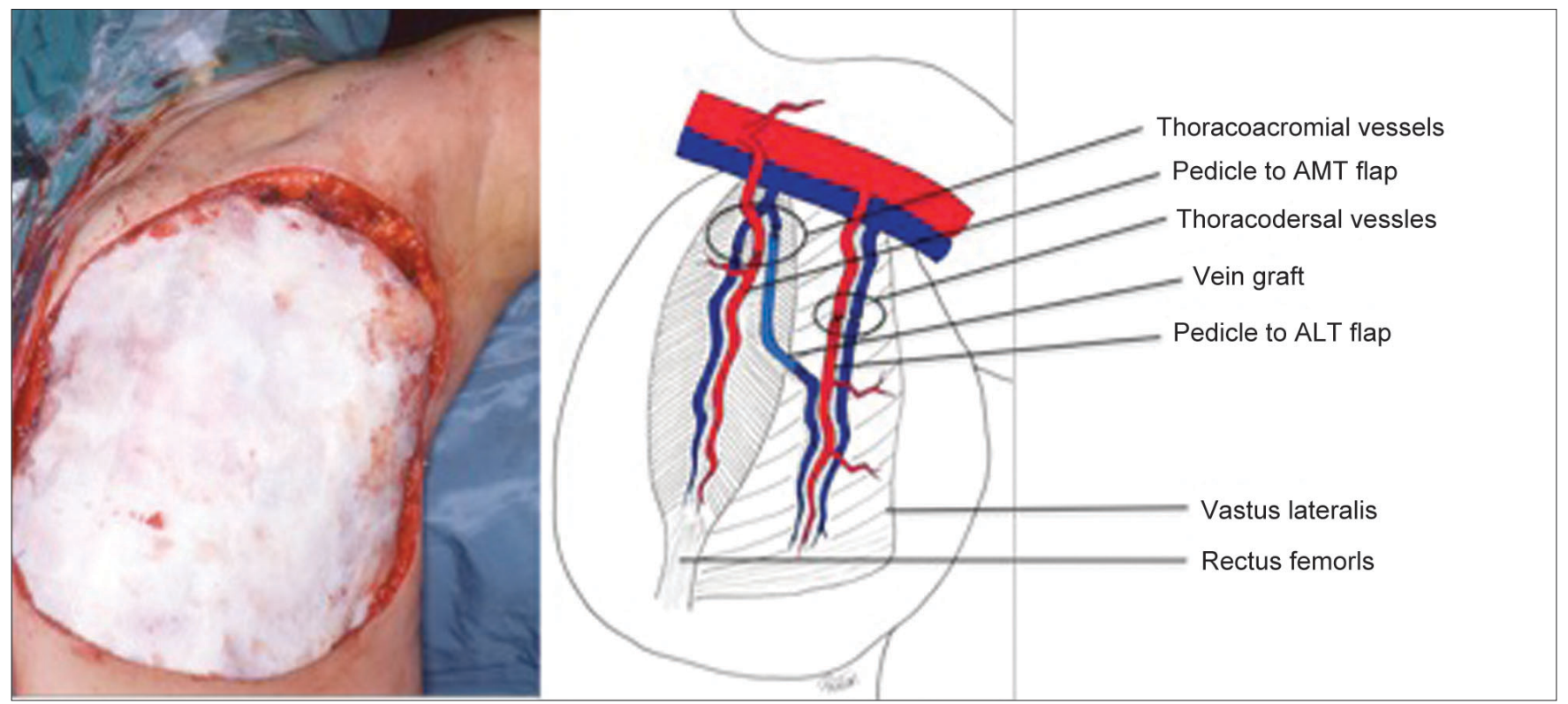

Figure 2: (a) Prolene mesh-methymethacrylate sandwich prosthesis, (b) Flap inset and revascularisation

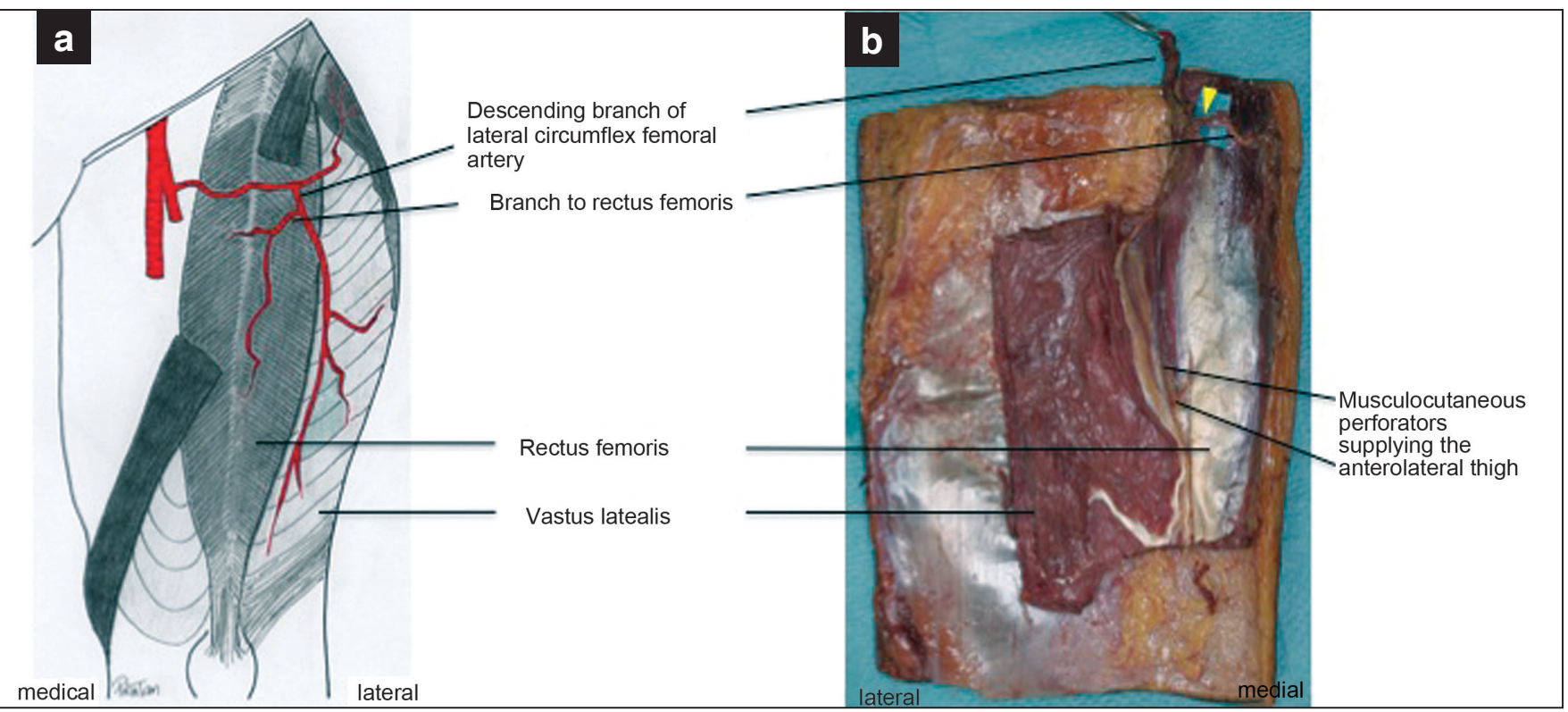

Figure 3: (a) Lateral circumflex femoral system supplying the rectus femoris and vastus lateralis muscles and (b) Cadaveric specimen showing the design of the flap. Note the pedicle to the anteromedial thigh

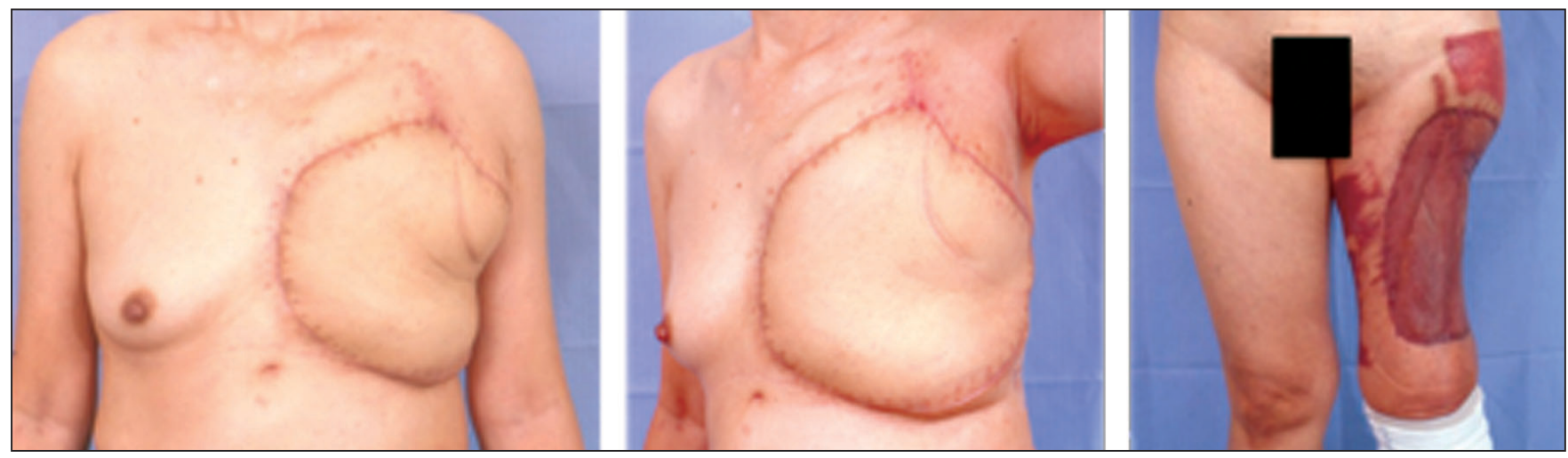

Figure 4: Six months postoperatively 
intercostal muscles and ribs 4-9 with underlying pleura, leaving a $25 \mathrm{~cm} \times 20 \mathrm{~cm}$ defect. Both internal mammary arteries were ligated during resection.

Skeletal reconstruction was performed with a Prolene mesh-methymethacrylate cement sandwich [Figure 2a], followed by immediate soft-tissue reconstruction. We harvested a combined musculocutaneous anterolateral thigh (ALT) with anteromedial thigh (AMT) flap, including the vastus lateralis and rectus femoris muscles, giving us two separate pedicles.

The flap was revascularised using two sets of recipient vessels, namely the thoracodorsal and the thoracoacromial arteries. Extra venous drainage was facilitated by a long saphenous Vein graft for the ALT [Figure 2b]. The donor site was skin grafted.

Postoperatively [Figure 3], the patient underwent radiotherapy. She was able to ambulate with a walking aid and lived for another 1 year before she succumbed to distant metastases [Figure 4].

\section{DISCUSSION}

The options for large chest wall defects range from local, pedicled (latissimus dorsi, pectoralis major, external oblique or rectus abdominis) muscle or free tissue transfer (single or multiple) according to Chang et al. ${ }^{\left[{ }^{11]}\right.}$ In our case, the ipsilateral latissimus dorsi could not be used as it was transected previously. The TRAM flap was precluded as both internal mammary vessels were ligated, and chasing what was left as a recipient vessel for a free TRAM would be challenging. Abdominal closure of a large TRAM would also lead to tension on the defect. Other free flap options were a large thigh flap or a contralateral latissimus dorsi flap. The latter was not chosen as it would require repositioning the patient during surgery.

Anterior thigh flaps provide bulk for contour deficiencies and excellent coverage of implants. ${ }^{[2]}$ The ALT flap has been popularized for its versatility and its vascular anatomy is well described. ${ }^{[3-6]}$ Most surgeons would limit its dimensions to $24 \mathrm{~cm} \times 12 \mathrm{~cm}$. To increase its dimension, we combined it with an AMT flap, resulting in a $25 \mathrm{~cm} \times 20 \mathrm{~cm}$ skin paddle. In the majority of cases, the AMT flap is supplied by perforators arising from the descending branch of the lateral circumflex femoral artery. Rarely, the perforators arise from the lateral circumflex femoral artery itself, ${ }^{[7]}$ the superficial femoral $\operatorname{artery}^{[8,9]}$ or directly from minor muscle branches to the rectus femoris. ${ }^{[10]}$ Our combined flap was supplied by the descending branch [Figure 2], but we separated it into two pedicles to improve circulationand safeguard against thrombosis. We included the vastus lateralis and rectus femoris to maximise muscle coverage, to improve local vascularity and offset the hard palpability of the underlying cement prosthesis. In addition, the tendinous portions of these muscles were anchored to the mesh-methylmethacrylate sandwich to prevent the flap from being dragged down by gravity. Lastly, we chose not to raise it as a perforator flap as experience has shown that very large ALT flaps based on even two to three perforators can still show marginal necrosis and, more importantly, laying bare perforators against a cement base would risk vessel spasm.

This patient had successful coverage of a large cement prosthesis with preservation of thoracic function. The main drawback was knee weakness from sacrifice of the vastus lateralis and rectus femoris muscles.

\section{ACKNOWLEDGMENT}

We thank Dr. Chew Khong Yik for helping us with the dissection of the cadaveric specimen.

\section{REFERENCES}

1. Chang RR, Mehrara BJ, Hu QY, Disa JJ, Cordeiro PG. Reconstruction of complex oncologic chest wall defects: A 10year experience. Ann Plast Surg 2004;52:471-9.

2. Ao M, Uno K, Maeta M, Nakagawa F, Saito R, Nagase Y. Deepithelialised anterior (anterolateral and anteromedial) thigh flaps for dead space filling and contour correction in head and neck reconstruction. Br J Plast Surg 1999;52:261-7.

3. Song YG, Chen GZ, Song YL. The free thigh flap: A new free flap concept based on the septocutaneous artery. Br J Plast Surg 1984;37:149-59.

4. Wong CH, Wei FC, Fu B, Chen YA, Lin JY. Alternative vascular pedicle of the anterolateral thigh flap: The oblique branch of the lateral circumflex femoral artery. Plast Reconstr Surg 2009;123:571-7.

5. Koshima I, Yamamoto H, Hosoda M, Moriguchi T, Orita $Y$, Nagayama $\mathrm{H}$. Free combined composite flaps using the lateral circumflex femoral system for repair of massive defects of the head and neck regions: An introduction to the chimeric flap principle. Plast Reconstr Surg 1993;92:411-20.

6. Baek SM. Two new cutaneous free flaps: The medial and lateral thigh flaps. Plast Reconstr Surg 1983;71:354-65.

7. Koshima I, Soeda S, Yamasaki M, Kyou J. The free or pedicled anteromedial thigh flap. Ann Plast Surg 1988;21:480-5.

8. Koshima I, Hosoda M, Inagawa K, Moriguchi T, Orita Y. Free 
Tan, et al.: Combined ALT and AMT flaps for chest wall reconstruction

medial thigh perforator-based flaps: New definition of the pedicle vessels and versatile application. Ann Plast Surg 1996;37: 507-15.

9. Xu Y, Shou K, Zhang Q. Transplantation of the remedial free anteromedial thigh flap. Zhonghua Zheng Xing Shao Shang Wai Ke Za Zhi 1996;12:407-9.

10. Hayashi $A$, Maruyama $Y$. The use of the anteromedial thigh fasciocutaneous flap in the reconstruction of the lower abdomen and inguinal region: A report of two cases. $\mathrm{Br} \mathrm{J}$ Plast Surg 1988;41:633-8

Source of Support: Nil, Conflict of Interest: None declared. 